\title{
Identifying spinner dolphin Stenella longirostris longirostris movement and behavioral patterns to inform conservation strategies in Maui Nui, Hawai'i
}

\author{
Stephanie H. Stack ${ }^{1, *}$, Grace L. Olson ${ }^{1}$, Valentin Neamtu ${ }^{1}$, Abigail F. Machernis ${ }^{1}$, \\ Robin W. Baird ${ }^{2}$, Jens J. Currie ${ }^{1}$ \\ ${ }^{1}$ Pacific Whale Foundation, Wailuku, HI 96793, USA \\ ${ }^{2}$ Cascadia Research Collective, Olympia, WA 98501, USA
}

\begin{abstract}
Spinner dolphins Stenella longirostris longirostris in Hawai'i exhibit a predictable diurnal behavioral pattern which makes them vulnerable to human disturbance: feeding at night in offshore waters and resting during daytime in bays. There is concern that human activity, such as swimming with and viewing wild dolphins from vessels, is altering their natural behavioral patterns and preventing them from having adequate rest. In light of this, state and federal management agencies are proposing enhanced protection measures. Research on spinner dolphins has largely focused off Hawai'i Island and there are insufficient data from Maui Nui (Maui, Lāna'i, Kaho'olawe, and Moloka'i) to inform appropriate management measures for the genetically distinct stock that resides around these islands. Using location data from 316 encounters between 1996 and 2019, we identified 2 hotspots for spinner dolphins within the region, located along west Maui and south Lāna'i. The predominant behavior observed was traveling, and there was little resting behavior documented throughout the study period, with no resting behavior observed along the coastline of Maui. Our findings revealed that spinner dolphins use a wide variety of available habitat in Maui Nui and were observed resting both near the shore of Lāna'i and in the channels between islands. Based upon these findings, the proposed lone area for closure in south Maui is inadequate for providing protection to spinner dolphins during resting hours, and we propose that the identified hotspots be considered as additional sites for closures, in addition to an approach limit for vessels transiting Maui Nui.
\end{abstract}

KEY WORDS: Spinner dolphins · Conservation $\cdot$ Tourism $\cdot$ Animal behavior $\cdot$ Hawai'i

\section{INTRODUCTION}

Spinner dolphins Stenella longirostris longirostris in Hawai'i are island-associated dolphins that exhibit a predictable daily diurnal behavioral pattern (Norris \& Dohl 1980, Lammers 2019). At night, spinner dolphins migrate offshore and feed cooperatively on vertically and horizontally migrating mesopelagic prey (Benoit-Bird \& Au 2009, Thorne et al. 2012). The dolphins typically enter shallow bays just after dawn and move into a resting state, characterized by slow, synchronized swimming, tight group formation, and

${ }^{*}$ Corresponding author: research@pacificwhale.org cessation of aerial behavior (Norris \& Dohl 1980). Resting dolphins move slowly for $4-5 \mathrm{~h}$ before beginning a zig-zag pattern of swimming, at which time surface activity begins to increase before the group migrates into deeper waters before dusk (Norris \& Dohl 1980). In the 1970s and early 1980s, several spinner dolphins were radio-tagged to monitor their nighttime movement patterns (Norris \& Dohl 1980, Norris et al. 1994); researchers learned that spinner dolphins move slowly offshore in the evening in large groups, zig-zagging back and forth along the island slope all night before approaching shore at dawn.

(C) The authors 2020. Open Access under Creative Commons by Attribution Licence. Use, distribution and reproduction are unrestricted. Authors and original publication must be credited. 
Spinner dolphins are distributed throughout the main Hawaiian Islands and the Northwestern Hawaiian Islands. Norris \& Dohl (1980) described spinner dolphin distribution throughout the Hawaiian archipelago and provided insight into dolphins' general movement patterns in the Maui Nui region-comprising the 4 islands of Maui, Lāna'i, Moloka'i, and Kaho'olawe. However, these data are outdated and lack photographic matches of individuals to assess inter- and intra-island movement patterns and interchange. There is significant genetic differentiation between spinner dolphins in Hawaiian waters and those found globally (Andrews et al. 2006). Further, genetic differentiation was found between individuals sampled at 5 different areas along the Hawaiian archipelago, suggesting that the Hawaiian Islands dolphins have low levels of population exchange and exhibit strong site fidelity (Andrews 2009, Andrews et al. 2010). Based upon the genetic differentiation between these areas, NOAA Fisheries defined 5 distinct island-associated stocks of spinner dolphins in Hawai'i: Hawai'i, O'ahu/4-islands (including Maui, Lāna'i, Moloka'i, and Kaho'olawe), Kaua'i/Ni'ihau, Pearl and Hermes Reef, and Midway Atoll/Kure (Carretta et al. 2014).

Extensive research on the distribution, abundance, and habitat use of spinner dolphins along the western coast of Hawai'i Island has been undertaken, particularly in the last $10 \mathrm{yr}$ (e.g. Norris et al. 1994, Thorne et al. 2012, Tyne et al. 2014, 2015, 2017). However, comparatively little is known about the movements and interchange of spinner dolphins around the other main Hawaiian Islands (Kaua'i/Ni'ihau, O'ahu, and Maui Nui). Previous research off the island of $\mathrm{O}^{\prime} \mathrm{ahu}$ found that spinner dolphins were resting in areas that were not considered ideal according to the findings of earlier researchers, such as outside of bays or milling along coastlines (Lammers 2004). In a later study, Thorne et al. (2012) modeled the characteristics of bays to determine if they could predict where spinner dolphins rested. From this spatial modeling, 4 bays were identified as suitable resting habitats in Maui Nui (Thorne et al. 2012), but these results could not be validated due to lack of available sighting data in this region. Recently, a study in Maui Nui by McElligott (2018) used acoustic data to propose that spinner dolphins utilize both the Maui coastline and the 'Au'au Channel to rest rather than one specific bay, as described for Hawai'i Island - but this, again, could not be validated due to a lack of sightings in this region. Maui Nui is of particular interest due to its unique shallow bathymetry between the 4 islands (see Fig. 2), compared to the steeper slopes leading offshore where spinner dolphins usually occur around the islands of Hawai'i and O‘ahu (McElligott 2018).

Predictable patterns of distribution and daytime behaviors of spinner dolphins in Hawai'i make them easily accessible to the public and vessel-based ecotourism activities, such as swimming with dolphins and whale watching. However, dolphin-directed activities that closely approach, swim with, interact with, and/or attempt to interact with dolphins have the potential to disrupt their normal behavioral patterns. Disturbance behaviors in response to vessels and swimmers have been documented for spinner dolphins (e.g. Courbis \& Timmel 2009, Tyne et al. 2018) and have been shown in other cetaceans to result in biologically significant consequences, such as habitat abandonment, decreased time spent foraging, and reduced reproductive success (Bejder et al. 2006a,b, Williams et al. 2006, Lusseau \& Bejder 2007). The primary concern for spinner dolphins is that human activities can cause disruption of the normal rest cycle and that inadequate quantity and/or quality of rest can have cumulative impacts that will affect life history processes, such as foraging and reproduction. Off Hawai'i Island there is evidence that the spinner dolphin population size has declined over several decades, likely as a result of long-term sustained pressure from human activities (Tyne et al. 2014). Additionally, Baird (2016) suggested that displacement from traditional shallow, nearshore resting grounds could also lead to increased predation by sharks, which are common in Hawai'i.

To effectively understand the overlap of spinner dolphins with anthropogenic activity first requires an understanding of how this population uses an area. Kernel density estimates of individual home ranges are the preferred method for assessing distribution (Rayment et al. 2009), as it can provide the range extent of an individual as well as insight into how an animal uses this range (Vokoun 2003).

In order to effectively manage human disturbance to spinner dolphins in Hawai'i, the National Marine Fisheries Service (NMFS) is evaluating additional protection measures to reduce harassment from vessel and swim-with activities (NOAA 2016a). Currently, the federal Marine Mammal Protection Act (1972) prohibits the harassment of spinner dolphins, but this term is vague and open to interpretation. Proposed regulatory measures include vessel approach regulations in coastal waters where dolphin-directed activities occur (within 2 nautical miles of each of the main Hawaiian Islands) and in designated waters between the islands of Lāna'i, Maui, and Kaho'olawe (NOAA 2016a). In NMFS's Draft Environmental 
Impact Statement (DEIS), various alternative actions were considered to enhance protection for spinner dolphins, including an approach limit which would prohibit vessels and swimmers from approaching spinner dolphins within 50 yards (46 m) and/or timearea closures for essential daytime habitat where consistent human-directed activities occur. In 2016, NOAA published a proposed rule in the Federal Register to establish a 50 yard $(46 \mathrm{~m})$ swim-with and approach regulation for spinner dolphins under the Marine Mammal Protection Act (NOAA 2016b). However, this proposed rule, and other management measures, are still under consideration.

In this study, we used photo-ID data collected from 1996-2019 to identify and document important spinner dolphin habitat in Maui Nui and characterize the amount of movement between the 4 islands of Maui Nui. We provide a baseline of spinner dolphin habitat use and behavior patterns in Maui Nui which can be used to measure the efficacy of the proposed enhanced protections. This information builds upon the existing body of knowledge about abundance, behavior, and genetic relatedness of spinner dolphins throughout the Hawaiian archipelago by characterizing their distribution and movement within Maui Nui, which can be used to inform appropriate conservation measures.

\section{MATERIALS AND METHODS}

\subsection{Study area}

The study area was within the nearshore waters of Maui Nui, which is semi-enclosed by the islands of Maui, Moloka'i, Lāna'i, and Kaho'olawe (Fig. 1). The islands are connected by the 'Au'au Channel between Lāna'i and west Maui, the Kealaikahiki Channel between Lāna'i and Kaho'olawe, and the 'Alalākeiki Channel between south Maui and Kaho'olawe. Surveys extended from leeward shores into waters approximately $20 \mathrm{~km}$ southwest of Lāna'i. The study area covered $2102 \mathrm{~km}^{2}$ and consisted predominantly of nearshore habitats with gently sloping shoreline gradients that extend to more complex bathymetry of seamounts and ridgelines (Grigg et al. 2002). The majority of the study area consisted of drowned reef features and sandy basins with a depth of $<200 \mathrm{~m}$; however, some areas south of Lāna'i reach depths up to approximately $600 \mathrm{~m}$ (Fig. 2)

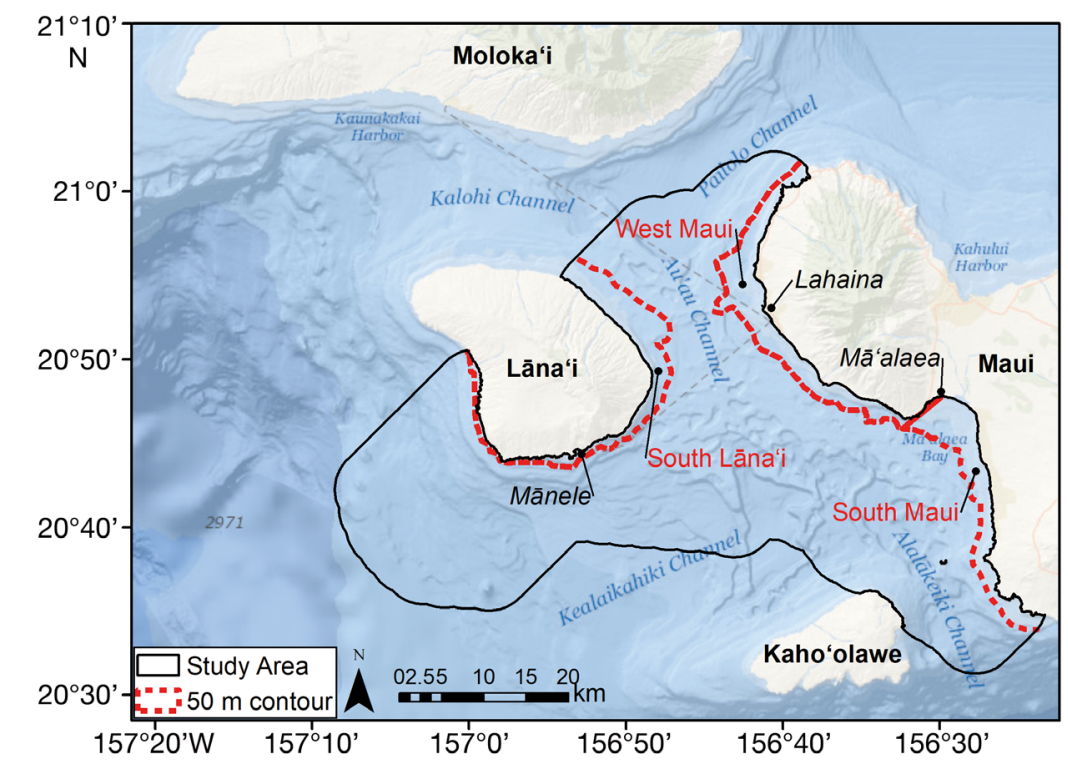

Fig. 1. Study area for spinner dolphin surveys conducted between June 1996 and August 2019, with boundary (solid black) based on the available survey effort data (2010-2019). Dashed red line: $50 \mathrm{~m}$ contour line used to divide nearshore from channel waters sightings

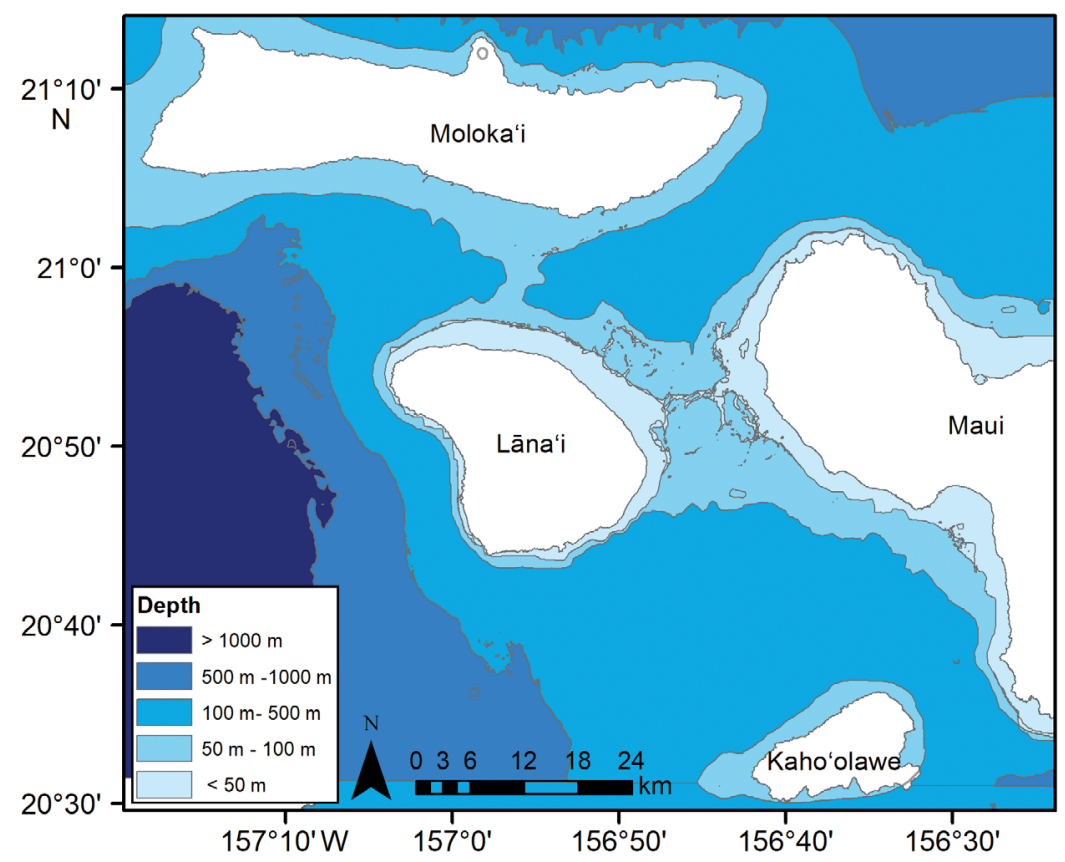

Fig. 2. Maui Nui region, with bathymetric contours showing the slope and gradient of the sea floor throughout our study site 


\subsection{Data collection}

Photo-ID surveys were conducted from a variety of research vessels from 1 June 1996 to 13 August 2019, with supplementary photo-ID data provided by Cascadia Research Collective for 2000-2003, 2012, and 2017. Vessels departed from Mā'alaea or Lahaina Harbor, Maui, or Mānele Harbor, Lāna'i. During each survey, a minimum of 2 observers and the captain scanned the water by naked eye, with an additional crew member acting as the data recorder. When spinner dolphins were sighted, a focal follow was initiated to confirm group size and location and collect photoID data and behavioral observations. Additional information on survey methodology is provided in Stack et al. (2019) and Baird et al. (2013).

\subsection{Data analysis}

\subsubsection{Photo identification}

Spinner dolphins were individually identified from photographs using the notches and other natural marks on their dorsal fins (Hammond et al. 1990). Photo quality criteria followed methods outlined in Urian et al. (2015) and were based on evaluating the focus, exposure, size, and angle of the animal in the photograph. Only photographs of individual spinner dolphins with distinctive marks on the dorsal fin (Urian et al. 2015), identified from good or excellent photos, were included in the catalog and used for subsequent analysis. All photographs were cataloged using Discovery Photo-ID software (Gailey \& Karczmarski 2012); matches were made using FinFindR software (Thompson 2018) and R v.3.5 (R Core Team 2019), then confirmed with naked eye (Markowitz et al. 2003). All matches and new individuals were independently verified by 2 other researchers to reduce matching error.

\subsubsection{Spatial analysis}

All spinner dolphin sightings with available location data and survey effort were imported into ArcGIS v.10.7 (ESRI) and assigned a WGS 1984 geographic coordinate system with a WGS 1984 World Mercator projection. The location of a dolphin group was represented by the start coordinates of the sighting, as not all sightings had end coordinates available for the entire study period, precluding the calculation of an encounter centroid.
The study area was divided into nearshore waters or the channel waters for each island where sightings occurred (Maui, Lāna'i, and Kaho'olawe). Nearshore waters were defined as the area between the shoreline and the $50 \mathrm{~m}$ contour line, as this depth range is a known predictor for spinner dolphin habitat use (Lammers 2004, Thorne et al. 2012). The channel waters were characterized by sightings that occurred outside the $50 \mathrm{~m}$ contour line (Fig. 1). Sightings along the coast of Maui were not continuous along the shoreline and were therefore further divided into 2 more regions referred to as south Maui and west Maui, separated by approx. $25 \mathrm{~km}$ (Fig. 1). This resulted in the division of the study area into 5 regions with spinner dolphin sightings: south Maui, west Maui, Lāna'i, Kaho'olawe, and channel waters.

Individual spinner dolphins that had at least one re-sighting were used to determine the amount of interchange between the 5 regions of Maui Nui. To provide a relative quantification of the amount of movement within Maui Nui, an index of interchange, taken from Urban et al. (2000), was calculated for each pairwise comparison of the 5 regions using the following formula:

$$
\text { Interchange index }=\left(m_{12} /\left[n_{1} \times n_{2}\right]\right) \times 1000
$$

where $n_{1}$ is number of spinner dolphins identified (marked) in region $1 ; n_{2}$ is number of spinner dolphins identified in region 2 ; and $m_{12}$ is the identified spinner dolphins matched between regions 1 and 2 .

A high value for the interchange index can indicate that either (1) a small population is present in the 2 regions or (2) there is a high probability of the same individual being sighted within both regions. In contrast, a low value for this index reflects a low probability of re-sighting due to either (1) a large population or (2) an unlikely interchange of animals between the 2 regions (Urban et al. 2000).

Kernel density estimates were calculated for adult individuals that were observed on a minimum of 15 occasions, as this is considered the minimum number of sightings required for this type of analysis (Rayment et al. 2009). To account for potential temporal autocorrelation, individual sightings were restricted to one per day, and if an individual was observed multiple times in a single day, only the first sighting was used. Kernel density estimates for each dolphin were calculated following MacLeod (2013) using the 'Kernel Interpolation With Barriers' tool in ArcGIS v.10.7 to account for the influence of the islands of Maui, Moloka'i, Lāna'i, and Kaho'olawe on subsequent estimates. The output grid cell size was set to $1 \times 1 \mathrm{~km}$ $\left(1 \mathrm{~km}^{2}\right)$ with the extent set to the perimeter of the 
survey area. Bandwidth was calculated using least squares cross validation (Bowman \& Azzalini 1997) and estimated at $5320 \mathrm{~m}$. The kernel function was set to a first order polynomial and the ridge parameter retained the default value of 50 .

The resulting kernel density estimates represent the estimated number of sightings per $\mathrm{km}^{2}$ that are likely to occur within each grid cell. Following Sprogis et al. (2016), the utilization distribution within the study area was determined from these values and defined as the minimum area in which an individual had a $95 \%$ probability of being sighted (Worton 1995). The $95 \%$ utilization distribution was determined following MacLeod (2013) by calculating the threshold value that included $95 \%$ of all sightings used to create the kernel density estimate for each individual. The $95 \%$ utilization distribution for each individual is hereafter referred to as the home range within the study area; however, it is important to note that the $95 \%$ utilization distribution represents the minimum expanse of each individual within the study area only, and the true distribution likely extends beyond the sampled areas.

Transect survey effort was collected using a Garmin handheld GPS from 2010-2019. The actual survey effort is greater than what is reported here, because GPS tracks were not consistently recorded prior to 2010. To account for uneven survey coverage, effort-corrected sightings were calculated by adapting methods presented in MacLeod (2013) as follows: a $1 \times 1 \mathrm{~km}$ grid cell was created to cover the survey area, and the group sightings per unit effort (sightings $\mathrm{km}^{-1}$ ) were calculated for each cell by dividing the number of encounters by the length of track line $(\mathrm{km})$ surveyed within the same cell. Grid cells with less than $1.41 \mathrm{~km}$ of survey effort (the linear distance required to diagonally traverse a $1 \mathrm{~km}^{2}$ grid cell) were dropped in the subsequent analysis to minimize the potential bias from poorly surveyed grid cells. This resulted in effort-corrected sightings throughout the study area with units of density (sightings $\mathrm{km}^{-1}$ ) per square kilometer.

Methods for the hotspot analysis were replicated from Smith et al. (2013) using the 'Getis-Ord $G_{i}^{*}$ ' statistic (Getis \& Ord 1992) to examine clustering patterns in the effort-corrected dolphin sightings. Analysis was completed in ArcGIS v.10.7 using the 'Hot Spot Analysis Tool'. To determine the appropriate spatial scale for analysis, both the distance threshold (in which spatial autocorrelation occurs) and peaks were calculated. The distance threshold of spatial autocorrelation in dolphin group locations was determined using the 'Average Nearest Neighbor' tool, while the 'Incremental Spatial Autocorrelation' tool was used to determine the distance at which spatial autocorrelation peaked. These distances were then used to create a custom spatial weights matrix, which defined a minimum of 8 neighboring cells (Getis \& Ord 1992) in which to calculate the local sum for each grid cell. The spatial weights matrix was then used as an input parameter for the 'Hot Spot Analysis Tool' to determine spinner dolphin group hotspots.

\subsubsection{Behavioral analysis}

Behavioral data were available for sightings in south and west Maui, Lāna'i, and channel waters, ranging from 24 July 1996 to 13 August 2019. At the conclusion of each focal follow, the predominant behavioral state of the group (i.e. more than $50 \%$ of the individuals displaying this behavior for more than $50 \%$ of the encounter) was determined to be the representative behavioral state for that focal follow. Behavioral states were classified into the following categories: (1) resting, (2) milling, (3) traveling, (4) feeding, or (5) socializing. It is important to note that no feeding behaviors were observed during the study period. Socializing behavior was observed during the study period, but did not constitute more than $50 \%$ of the encounter. As such, these 2 behavioral states were excluded from subsequent analyses (Table 1).

Time intervals for behavioral observations were adapted from Lammers (2004) with the expansion of the early morning category to include 06:00-06:59 h, as follows: early morning (06:00-10:00 h), late morning (10:01-12:00 h), mid-day (12:01-14:00 h), and early afternoon (14:01-16:00 h). No spinner dolphin sightings occurred later than $16: 00 \mathrm{~h}$ during the study period. The proportion of time that dolphins in each location spent in each behavioral state during

Table 1. Behavioral states of spinner dolphin groups, adapted from Lusseau (2003)

\begin{tabular}{|ll}
\hline Behavioral state & Definition \\
\hline Traveling & $\begin{array}{l}\text { Group moves steadily in a constant } \\
\text { direction; group spacing varies }\end{array}$ \\
& $\begin{array}{l}\text { Group moves slowly in a constant } \\
\text { direction with short relatively con- } \\
\text { stant, synchronized dives; individu- } \\
\text { als are tightly grouped } \\
\text { Milling }\end{array}$ \\
& $\begin{array}{l}\text { Group has no net movement, with } \\
\text { frequent direction changes and indi- } \\
\text { viduals facing different directions; } \\
\text { group spacing varies }\end{array}$ \\
\hline
\end{tabular}


each of these time intervals was calculated by dividing the count of each behavior state by the total number of observations.

\section{RESULTS}

Overall, there were 1015 days of effort and 316 spinner dolphin encounters, supplemented by an additional 132 days of effort and 21 spinner dolphin encounters by Cascadia Research Collective. Groups sizes encountered ranged from 2-300 individuals $($ median $=93)$.

\subsection{Photo-ID}

Throughout the study period, 685 unique spinner dolphins were identified over 337 encounters, with dorsal fin identification photos available for each encounter. The number of resightings for individual dolphins ranged from 0-18, with 337 individuals (49.2\%) having at least one re-sighting. Two individuals had re-sighting histories that spanned the entire duration of the study period (23 yr).

\subsection{Spatial analysis}

Lāna'i had the largest number of unique individual identifications ( $\mathrm{n}=$ 444), followed by channel waters ( $\mathrm{n}=$ 226), west Maui ( $\mathrm{n}=90)$, south Maui ( $=48)$, and Kaho'olawe $(\mathrm{n}=21)$. In total, $71 \%$ of all individuals with 2 or more sightings were observed moving between at least 2 of the 5 regions throughout the study area, often between islands. Pairwise comparisons between the 5 regions within Maui Nui found spinner dolphins sighted between Kaho'olawe and Lāna'i to have the highest value of interchange (14.08); the next highest levels of interchange occurred between west Maui and Lāna'i (10.02), and channel waters and Lāna'i (9.70) (Table 2).

The home range of 7 individuals with more than 15 re-sights ranged from 94-164 $\mathrm{km}^{2}$ (median: $114 \mathrm{~km}^{2}$ ) and showed a high degree of overlap
(Fig. S1 in the Supplement at www.int-res.com/ articles/suppl/m644p187_supp.pdf). The home ranges were concentrated within south Lāna'i, the 'Au'au Channel, and west Maui waters. However, the home range of 1 of the 7 individuals spanned 4 of the 5 sighting areas of Maui Nui, with distributions separated by over $35 \mathrm{~km}$ (Fig. S1D).

After removing 263 cells with no or low survey effort, 1839 grid cells and 234 encounters were used in the hotspot analysis. Of these 1839 grid cells, spinner dolphin encounters were recorded in 104 cells, and of these, 33 effort-corrected grid cells were identified as hotspots for spinner dolphins, having GetisOrd $G_{i}^{*}$ p-values of less than 0.05 (Table S1), representing an area of $33 \mathrm{~km}^{2}$. The 2 hotspot areas were split between west Maui and south Lāna'i (Fig. 3). The largest hot spot area was along the coast of Lāna'i, covering an area of $30 \mathrm{~km}^{2}$; this was also the region with the highest densities (sightings $\mathrm{km}^{-2}$ ) of

Table 2. Indices of interchange between Lāna'i, Maui, Kaho'olawe, and the channel waters, with the number of individual spinner dolphins identified at each location during the study period in parentheses

\begin{tabular}{|lccccc|}
\hline & $\begin{array}{c}\text { Lāna'i } \\
(\mathrm{n}=444)\end{array}$ & $\begin{array}{c}\text { South } \\
\text { Maui }\end{array}$ & $\begin{array}{c}\text { West } \\
\text { Maui }\end{array}$ & Kaho'olawe & $\begin{array}{c}\text { Channel } \\
\text { waters }\end{array}$ \\
\hline South Maui $(\mathrm{n}=48)$ & 3.68 & & & & \\
West Maui $(\mathrm{n}=90)$ & 10.02 & 3.29 & & & \\
Kaho'olawe (n=21) & 14.08 & 2.29 & 4.76 & & \\
Channel waters (n = 226) & 9.70 & 4.53 & 5.26 & 7.63 & \\
\hline
\end{tabular}

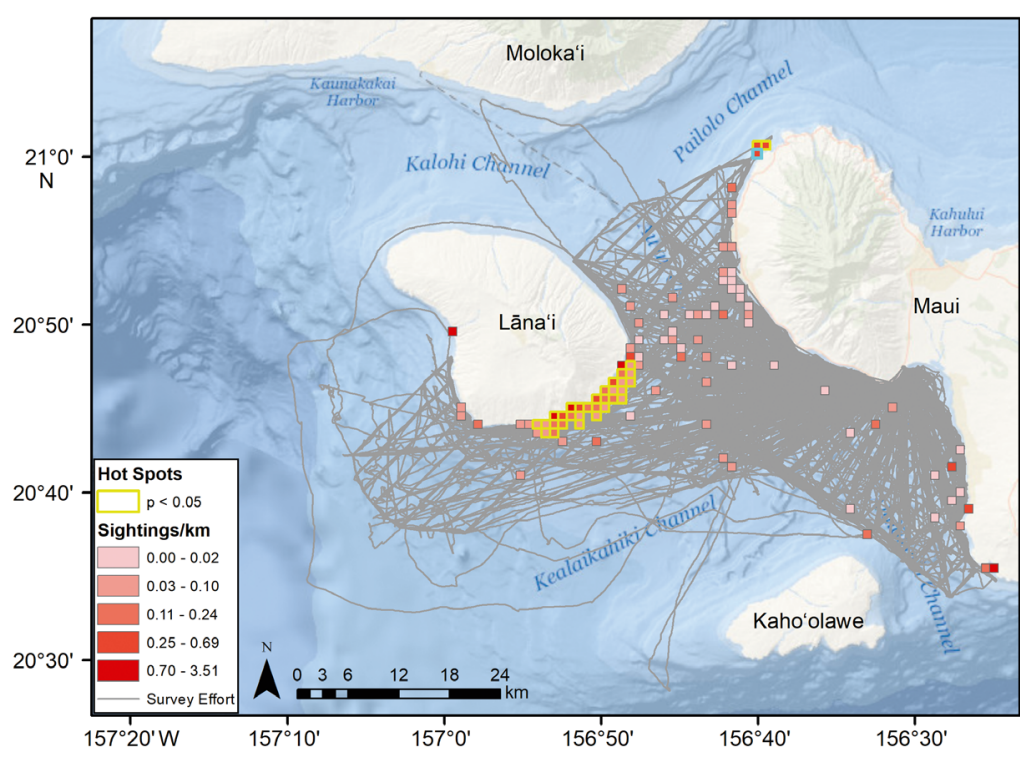

Fig. 3. Survey effort (grey lines), density of sightings in each $1 \mathrm{~km}^{2}$ grid cell, and significantly significant $(\mathrm{p}<0.05)$ hot spots of spinner dolphins in Maui Nui (yellow) 
spinner dolphins. The highest observed spinner dolphin densities (1.5-3.5 sightings $\mathrm{km}^{-2}$ ) were restricted to the nearshore region of Lāna'i, within $1 \mathrm{~km}$ of the shoreline (Fig. 3). Single high-density grid cells ( $>0.70$ sightings $\mathrm{km}^{-2}$ ) were also identified in the nearshore waters of south Maui but were not determined to be hotspots, as they did not exhibit clustering at the selected spatial resolution.

\subsection{Behavioral analysis}

From the 23 yr data set, 77 encounters had recorded data on overall group behavior, which accounted for approximately $140 \mathrm{~h}$ of observation across the 4 locations (south Lāna'i: 89 h; south Maui: 10 h; west Maui: 19 h; channel waters: 24 h). Spinner dolphin behaviors varied by location, with traveling behavior accounting for the majority (61.8\%) of observation time across all locations (Fig. 4). Resting behavior was observed along the south Lāna'i coast and in channel waters, and occurred mostly in the early and late morning time periods. Traveling was the most prominent behavior observed in channel waters, accounting for $100 \%$ of observations during the mid-day and late afternoon time periods (Fig. 4C). Resting behaviors were not observed at any location in the early afternoon time period.

\section{DISCUSSION}

Knowing where spinner dolphins spend their time is a key component of developing protective measures that will be effective in mitigating the significant tourism pressures they are experiencing. Here, we provide data on the movement and behavioral patterns of spinner dolphins within Maui Nui to inform and guide the most appropriate way to conserve this population.

\subsection{Spatial analysis}

The overall trend in area use documented in this study differs from previous research on spinner dolphins, which had indicated that these animals rest primarily in shallow bays and protected coves, while areas outside of bays are used for transiting between the resting and feeding areas (Tyne et al. 2015). Our
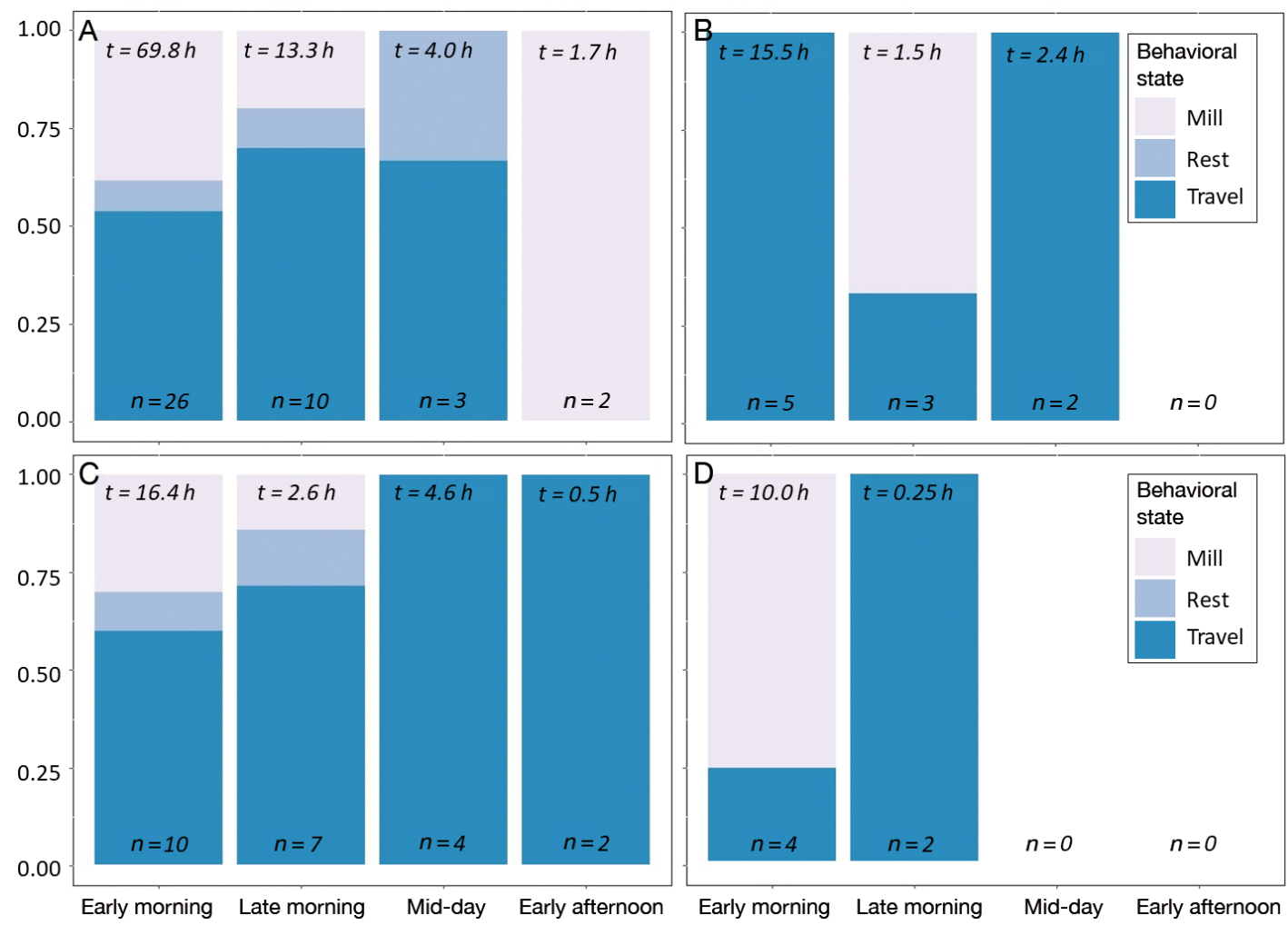

Fig. 4. Number of focal follows for each area $(n)$, number of hours included $(t)$, and proportion of time spinner dolphins spent in each behavioral state during focal follows in (A) Lāna'i, (B) west Maui, (C) channel waters, and (D) south Maui. Behavioral data was not available for the Kaho'olawe encounters 
findings revealed that spinner dolphins use a wide variety of available habitat in the Maui Nui area and were observed resting both near shore and in the channels between islands. Sightings of individuals occurred near multiple islands in Maui Nui, demonstrating that the dolphins documented in this study do not show fidelity to any one particular location but rather move between areas. The channel waters appear to be a transition zone between coastal areas, as there are high degrees of interchange between the channel waters and the shoreline hotspots. The reason for these differences is likely due to the unique nature of the islands comprising Maui Nui. During the last glacial maximum, about $21000 \mathrm{yr}$ ago, the islands of Maui, Lāna'i, Moloka'i, and Kaho'olawe were connected by limestone land bridges, creating a 'super island' called Maui Nui (Grigg et al. 2002). As such, the water depth in the channels between these islands is relatively shallow compared to the steep drop-offs along the coasts of the other Hawaiian Islands.

The home ranges of individual dolphins were calculated to determine the areas in Maui Nui that are utilized by spinner dolphins and to quantify the amount of individual variation in their distribution. While we acknowledge the sample size is small for this calculation (which represents a limitation in kernel density estimation), results show that individual spinner dolphins do not use the area equally, which is an important consideration when planning conservation measures. If area closures are being considered, data are needed about what locations are occupied by spinner dolphins and about how much movement occurs between these areas. The individuals with a sufficient number of re-sightings to be included in the calculation all showed different home ranges but all included the area along the south coast of Lāna'i island.

\subsection{Behavioral analysis}

Spinner dolphins sighted along west and south Maui were milling or traveling throughout our observations, and it is of concern that no resting behavior was documented during the study period in these 2 locations. However, the sample size of available behavioral data from these localities were lower than for Lāna'i or the channel, so additional data are needed to assess resting behavior off Maui. Spinner dolphins are a major tourism attraction in Hawai'i (Wiener 2016), and concerns have arisen about their exposure to human disturbance during their daytime resting hours. For example, Tyne et al. (2018) found that spinner dolphins off the Kona coast of Hawai'i were exposed to human activity, such as vessel traffic and swimmers, within $100 \mathrm{~m}$ for $82 \%$ of their daytime resting hours. Without additional data it is difficult to say if spinner dolphins should be resting in these locations and are already experiencing changes in their behavioral patterns from human activities, or if this is normal spinner dolphin behavior for this stock. Along Lāna'i and in the channel waters, spinner dolphins were observed to be either traveling, milling, or resting, with a typical pattern of decreased resting and increased traveling as the day progressed. The behavioral patterns observed could indicate that, due to human activities, these dolphins are experiencing decreased opportunities to rest in the daytime hours, forcing them to travel more in search of an appropriate place to rest. Throughout Maui Nui, there is moderately heavy vessel traffic from numerous ferries, commercial, and private vessels $(<65 \mathrm{ft} ; 20 \mathrm{~m})$ that are increasing underwater sound, navigating in close proximity to the dolphins, and/or adding swimmers to the water.

The body of knowledge on spinner dolphins in the Hawaiian archipelago is weighted heavily towards research conducted on the Hawai'i island stock (e.g. Norris et al. 1994, Thorne et al. 2012, Tyne et al. 2014, 2015). In this study, we present findings specific to Maui Nui that can be used to inform the most appropriate management strategy for the O'ahu/4-island stock. We used photo-ID to confirm the movement and area use of individual dolphins to build upon our knowledge of spinner dolphin distribution and area use in the Hawaiian Islands by adding the first record specific to spinner dolphins in Maui Nui.

\subsection{Conservation implications}

Based on our analyses, we recommend a combination of the 2 enhanced management measures that have been proposed: (1) implementing a 50 yard (46 m) approach limit throughout the waters of Maui Nui, and (2) time-area closures for the spinner dolphin hotspots along the coasts of west Maui and south Lāna'i.

Spinner dolphins in Maui Nui use a wide variety of available habitat for resting, some of which is not nearshore and, as such, poses challenges to close this area to vessel traffic. The 50 yard $(46 \mathrm{~m})$ approach limit, which is consistent with the guidelines from the Dolphin SMART program, would be successful in mitigating some of the disturbance to spinner dol- 
phins that are resting in the channel waters or transiting between areas, as there is currently no legal approach distance that vessels must follow for spinner dolphins (NOAA 2016a).

Implementing area closures within the 2 identified hotspots would be the most effective means for providing protection against human disturbance. Unfortunately, the lack of available data on spinner dolphins throughout the main Hawaiian Islands had made it challenging to identify important spinner dolphin habitat, and consequently the coastal area along west Maui was not considered in the DEIS. This hotspot analysis has identified important spinner dolphin habitat along west Maui and south Lāna'i that is distinct from the 2 areas considered in the DEIS. Within Maui Nui, 2 bays were evaluated for mandatory or voluntary time-area closures between 06:00 and 15:00 h: Hulopo'e Bay and La Perouse Bay (NOAA 2016a). Hulopo'e Bay, located in south Lāna'i adjacent to a privately owned park and the Four Seasons Mānele Bay Hotel, is a state-designated Marine Life Conservation District and is therefore closed to boat access; however, swimmers and snorkelers can enter from the outside edges of the bay or from the beach (Sepez 2006). Hulopo'e Bay did not meet the evaluation criteria to be considered for additional protection to spinner dolphins and was therefore not considered for time-area closure in the DEIS. La Perouse Bay, located in south Maui, is the only embayment within Maui Nui that met the criteria to be considered for additional time-area closure protections. La Perouse Bay is adjacent to the 'Āhihi Kinna'u Natural Area Reserve, which is protected by the State of Hawai'i and prohibits any commercial boating activity within the bay. However, the same protections do not apply to La Perouse Bay. Many guide books advertise this location as a well-known area to swim with wild spinner dolphins and it can be accessed from shore. No additional sites in Maui Nui were considered for time-area closures.

The lone proposed time-area closure in La Perouse Bay is insufficient to provide adequate protection to the genetically distinct spinner dolphins in the $\mathrm{O}^{\prime} \mathrm{ahu} /$ 4 -island stock. Our findings show that many spinner dolphins do not use La Perouse Bay, and thus a large proportion of this stock would not be receiving protection from this measure.

Current stock boundaries for spinner dolphins in the Hawaiian archipelago are based upon genetic differences and photo-ID re-sight data (Hill et al. 2010). When the stock boundaries were redefined in 2010, the authors noted that the genetic differentiation between the Kaua'i/Ni'ihau stock, O'ahu/4-islands stock, and the Hawai'i island stock was sufficient to warrant separate management plans (Hill et al. 2010). Our findings reinforce the finding that stockspecific management is advisable to provide adequate protection to spinner dolphins throughout the Hawaiian Islands.

\subsection{Conclusions}

Our results are directly relevant to addressing the increasing tourism pressure on spinner dolphins in Hawai'i. Our research has shown that spinner dolphins rest both in the channel between Maui and Lāna'i and along the shoreline of Lāna'i. Therefore, the most effective way to offer protections to the O'ahu/4-islands stock is by implementing an approach distance for vessels in Maui Nui and instigating additional time-area closures for the 2 identified hotspots. These changes will bring us closer to the ultimate goal of mitigating environmental stressors from vessel-based tourism and allow spinner dolphins in Hawai'i to co-exist with the humans that are using these waters. Although survey effort was low near the island of Kaho'olawe, our sightings, combined with anecdotal data, suggest that this area is important for spinner dolphins and warrants further investigation. Additional research into spinner dolphin habitat use and behavioral patterns is needed throughout all the Hawaiian Islands and, in particular, evaluating the efficacy of the enhanced management measures after their implementation.

Acknowledgements. Funding for this work was provided by members and supporters of Pacific Whale Foundation and contracts and grants from NMFS (Southwest Fisheries Science Center and Pacific Islands Fisheries Science Center) as well as a contract from the State of Hawai'i to Cascadia Research Collective. We thank the many field team members over the years, both staff and volunteers, who contributed to our long-term spinner dolphin project. Thank you to the reviewers whose constructive feedback greatly improved the manuscript. Portions of this research were carried out under NMFS LOC 13427 and LOC 18101 issued to Pacific Whale Foundation and NMFS Permits No. 926, 731-1509, 15330 and 20605 issued to R.W.B.

\section{LITERATURE CITED}

Andrews KR (2009) Barriers to gene flow in the spinner dolphin (Stenella longirostris). PhD dissertation, University of Hawai'i

Andrews KR, Karczmarski L, Au WW, Rickards SH, Vanderlip CA, Toonen RJ (2006) Patterns of genetic diversity of the Hawaiian spinner dolphin. Atoll Res Bull 543:65-73 Andrews KR, Karczmarski L, Au WWL, Rickards SH and 
others (2010) Rolling stones and stable homes: social structure, habitat diversity and population genetics of the Hawaiian spinner dolphin (Stenella longirostris). Mol Ecol 19:732-748

Baird RW (2016) The lives of Hawai'i's dolphins and whales: natural history and conservation. University of Hawai'i Press, Honolulu, HI

Baird RW, Webster DL, Aschettino JM, Schorr GS, McSweeney DJ (2013) Odontocete cetaceans around the main Hawaiian Islands: habitat use and relative abundance from small-boat sighting surveys. Aquat Mamm 39:253-269

Bejder L, Samuels A, Whitehead H, Gales N and others (2006a) Decline in relative abundance of bottlenose dolphins exposed to long-term disturbance. Conserv Biol 20: 1791-1798

Bejder L, Samuels A, Whitehead H, Gales N (2006b) Interpreting short-term behavioural responses to disturbance within a longitudinal perspective. Anim Behav 72: 1149-1158

Benoit-Bird KJ, Au WW (2009) Cooperative prey herding by the pelagic dolphin, Stenella longirostris. J Acoust Soc Am 125:125-137

Bowman AW, Azzalini A (1997) Applied smoothing techniques for data analysis: the kernel approach with S-Plus illustrations. Oxford University Press, Oxford

Carretta JV, Oleson EM, Weller DW, Lang AR and others (2014) US Pacific marine mammal stock assessments, 2013. NOAA Tech Memo NOAA-TM-NMFS-SWFSC-532

Courbis S, Timmel G (2009) Effects of vessels and swimmers on behavior of Hawaiian spinner dolphins (Stenella longirostris) in Kealake'akua, Honaunau, and Kauhako bays, Hawai'i. Mar Mamm Sci 25:430-440

Gailey G, Karczmarski L (2012) Discovery: photo-identification data-management system for individually recognizable animals. www.biosch.hku.hk/ecology/staffhp/lk/ Discovery (accessed 7 March 2013)

Getis A, Ord JK (1992) The analysis of spatial association by use of distance statistics. Geogr Anal 24:189-206

Grigg R, Grossman E, Earle S, Gittings S, Lott D, McDonough J (2002) Drowned reefs and antecedent karst topography, Au'au Channel, SE Hawaiian Islands. Coral Reefs 21:73-82

Hammond PS, Mizroch SA, Donovan GP (eds) (1990) Individual recognition of cetaceans: use of photo-identification and other techniques to estimate population parameters. Rep Int Whal Comm Spec Issue 12

Hill MC, Oleson EM, Andrews K (2010) New islandassociated stocks for Hawaiian spinner dolphins (Stenella longirostris longirostris): rationale and new stock boundaries. Pacific Islands Fisheries Science Center administrative report no. H-10-04. NOAA, Honolulu, HI

Lammers MO (2004) Occurrence and behavior of Hawaiian spinner dolphins (Stenella longirostris) along O‘ahu's leeward and south shores. Aquat Mamm 30:237-250

Lammers MO (2019) Spinner dolphins of islands and atolls. In: Würsig B (ed) Ethology and behavioral ecology of odontocetes. Springer, Cham, p 369-385

Lusseau D (2003) Effects of tour boats on the behavior of bottlenose dolphins: using Markov chains to model anthropogenic impacts. Conserv Biol 17:1785-1793

Lusseau D, Bejder L (2007) The long-term consequences of short-term responses to disturbance experiences from whale watching impact assessment. Int J Comp Psychol 20:228-236
MacLeod CD (2013) An introduction to using GIS in marine biology: supplementary workbook four - investigating home ranges of individual animals. Pictish Beast Publications, Glasgow

Marine Mammal Protection Act (1972) 16 USC $\S \S 1361$ et seq.

Markowitz TM, Harlin A, Würsig B (2003) Digital photography improves efficiency of individual dolphin identification. Mar Mamm Sci 19:217-223

McElligott M (2018) Behavioral and habitat-use patterns of spinner dolphins (Stenella longirostris) in the Maui Nui region using acoustic data. MS thesis, University of Hawai'i at Manoa, Honolulu, HI

NOAA (2016a) Enhancing protections for Hawaiian spinner dolphins to prevent disturbance. Draft Environmental Impact Statement and Regulatory Impact Review, August 2016. NOAA Pacific Islands Regional Office, Honolulu, HI

NOAA (2016b) Protective regulations for Hawaiian spinner dolphins under the Marine Mammal Protection Act. Fed Regist 81:57854-57876

Norris KS, Dohl TP (1980) Behavior of the Hawaiian spinner dolphin, Stenella longirostris. Fish Bull 77:821-849

Norris KS, Würsig B, Wells RS, Würsig M (1994) The Hawaiian spinner dolphin. University of California Press, Berkeley, CA

R Core Team (2019) R: a language and environment for statistical computing. R Foundation for Statistical Computing, Vienna

Rayment W, Dawson S, Slooten E, Bräger S, Fresne SD, Webster T (2009) Kernel density estimates of alongshore home range of Hector's dolphins at Banks Peninsula, New Zealand. Mar Mamm Sci 25:537-556

Sepez J (2006) Human interactions with spinner dolphins (Stenella longirostris) in the main Hawaiian Islands: description and analysis of activities of concern and management options. Internal NOAA draft report, Pacific Island Regional Office and Alaska Fisheries Science Center, Seattle, WA

Smith HC, Pollock K, Waples K, Bradley S, Bejder L (2013) Use of the robust design to estimate seasonal abundance and demographic parameters of a coastal bottlenose dolphin (Tursiops aduncus) population. PLOS ONE 8: e76574

Sprogis KR, Raudino HC, Rankin R, MacLeod CD, Bejder L (2016) Home range size of adult Indo-Pacific bottlenose dolphins (Tursiops aduncus) in a coastal and estuarine system is habitat and sex-specific. Mar Mamm Sci 32: 287-308

* Stack SH, Currie JJ, McCordic JA, Olson GO (2019) Incidence of odontocetes with dorsal fin collapse in Maui Nui, Hawai'i. Aquat Mamm 45:257-265

*Thompson J (2018) finFindR: fin identification package. https://github.com/haimeh/finFindR/wiki (accessed 15 March 2018)

* Thorne LH, Johnston DW, Urban DL, Tyne J and others (2012) Predictive modeling of spinner dolphin (Stenella longirostris) resting habitat in the main Hawaiian Islands. PLOS ONE 7:e43167

* Tyne JA, Pollock KH, Johnston DW, Bejder L (2014) Abundance and survival rates of the Hawai'i Island associated spinner dolphin (Stenella longirostris) stock. PLOS ONE 9:e86132

Tyne JA, Johnston DW, Rankin R, Loneragan NR, Bejder L (2015) The importance of spinner dolphin (Stenella lon- 
girostris) resting habitat: implications for management. J Appl Ecol 52:621-630

Tyne JA, Johnston DW, Christiansen F, Bejder L (2017) Temporally and spatially partitioned behaviours of spinner dolphins: implications for resilience to human disturbance. R Soc Open Sci 4:160626

Tyne JA, Christiansen F, Heenehan HL, Johnston DW, Bejder L (2018) Chronic exposure of Hawai'i island spinner dolphins (Stenella longirostris) to human activities. R Soc Open Sci 5:171506

Urban JR, Jaramillo AL, Aguayo AL, Ladron de Gueva PP and others (2000) Migratory destinations of humpback whales wintering in the Mexican Pacific. J Cetacean Res Manag 2:101-110

Urian K, Gorgone A, Read A, Balmer B and others (2015)

Editorial responsibility: Stephen Wing,

Dunedin, New Zealand
Recommendations for photo-identification methods used in capture-recapture models with cetaceans. Mar Mamm Sci 31:298-321

Vokoun JC (2003) Kernel density estimates of linear home ranges for stream fishes: advantages and data requirements. N Am J Fish Manag 23:1020-1029

Wiener CS (2016) Understanding spinner dolphin marine tourism in Hawai'i: a social approach to assessing underwater interactions. PhD thesis, York University, Toronto

Williams R, Lusseau D, Hammond PS (2006) Estimating relative energetic costs of human disturbance to killer whales (Orcinus orca). Biol Conserv 133:301-311

Worton BJ (1995) Using Monte Carlo simulation to evaluate kernel-based home range estimators. J Wildl Manag 59: 794-800

Submitted: October 30, 2019; Accepted: April 22, 2020

Proofs received from author(s): June 22, 2020 